\title{
EVALUATION OF POLLUTION DAMAGE COST IN BELLANWILA ATTIDIYA WETLAND
}

\author{
S.H.B.N.P. Herath \& U.A.D.P. Gunawardene \\ Department of Forestry and Environmental Science, \\ University of Sri Jayewardenepura
}

Management of waste, both liquid and solid has become a critical environmental concern particularly in the more urbanized areas il Sri Lanka and this problem is most scvere in the densely populated areas of Western province. Bellanwila Attidiya wetland is also one of the places, which is used as open dumpsites. It has bad effects on the health, air quality, bio diversity water, and land.

The main objective of the present study was to evaluate the pollution damage cost of the wetland. In addition peoples views were also oblained on possibility of recreation in the wetland

In the present study the Contingent Valuation Method was used to evaluate the pollution damage cost of the wetland. Data was derived from a Contingent Valuation survey carricd out among the residents of the area and commuters who travel along the road which passes through the wetland. The results were consistent with theory and an aggregate cost of wetland pollution was estimated to be 287000 million rupees per year. People expressed their willingness for proposals of developing the wet land as a recreation site.

The valuation may be useful in cost benefit analysis of wetland management and other related policy and planning programmes rclated to wetlands. This could be uscd as an instrument to get the local and international attention and draw funds for the wetland conservation 